\title{
Prebiotic Inulin and Fructooligosachride as an Alternative Growth Promoter in Animal
}

\author{
Anjali Khare, Gaurav Thorat, Veena Mani*, Sachin Kumar, \\ Mamata Joysowal, A. Aziz and Supriya Gupta
}

Animal Nutrition Division, ICAR-National dairy Research Institute, Karnal 132001, India

*Corresponding author

\section{A B S T R A C T}

\section{Keywords}

Prebiotic, Chicory, Inulin, Growth

Article Info

Accepted:

08 June 2018

Available Online:

10 July 2018
Diarrhoea is the most common health concern and cause of death during the preweaning period. Ban on the use of antibiotics as growth promoters in the European Union since January 1, 2006 (EC 2001) alternative prebiotic come in existence. Prebiotic supplementation improves gastrointestinal health and immune function in livestock. Inulin type prebiotics occupies top position in the list of prebiotics because of their availability from a wide resources with minimum cost involvement and includes a group of biomolecules viz.; inulin, oligofructose and fructo-oligosaccharides Inulin is one of the fructans, naturally occurring in many plants, mostly extracted from chicory root (Cichorium intybus).So the effect of prebiotic on growth performance, faecal characteristic, immunity and antioxidant are presented

\section{Introduction}

Nowadays, besides the basic role of nutrition consisting in the supply of essential nutrients for growth and development of the organism, some additional aspects are becoming increasingly important, including the maintenance of health and counteracting diseases. In the world of highly processed food, particular attention is drawn to the composition and safety of consumed products.ban on the use of antibiotics as growth promoters in the European Union since January 1, 2006 (EC 2001) urged the scientist to find suitable alternatives to antibiotics. Moreover, therapeutic benefits from antibiotics also possibly diminish with long term use. To overcome these problems and to replace the use of antibiotics prebiotics came up as a good adjuvant to promote the health (Heinrich et al., 2003). Prebiotics are nondigestible food ingredients when taken sufficiently, selectively stimulate the growth and activity of one or a limited number of microbes in the gut that can improve the host health.

There are number of prebiotics with different origin and chemical properties. Stowell (2007) classified prebiotics into established and emerging. Inulin, fructo oligosaccharides (FOS), galacto oligosaccharides (GOS), 
lactulose and polydextrose come under established prebiotics whereas isomaltooligosaccharides (IMO), xylooligosaccahrides (XOS), and lactitol come under emerging prebiotics. Prebiotics have also been classified into short chain, long chain and full spectrum prebiotics. Short chain prebiotics like oligofructose have 2-8 links per saccharide molecule which are readily fermented in the right side of colon thus support bacterial growth in that area. Long chain prebiotics like inulin contain 9-64 links per saccharide molecule that are slowly fermented and proliferate bacteria on left side of colon. Full-spectrum prebiotics like oligofructose enriched inulin (OEI) provide molecular link-lengths from 2-64 links per molecule, and nourishes bacteria throughout the colon.

Inulin and its different forms are present in a wide variety of plants as natural storage carbohydrates. It was first discovered as a "peculiar substance" by German scientist Rose in the year 1804 from the hot water extract of roots of plants (Inulahelenium) belonged to Compositae family. Later on, the term "Inulin" was coined by Thomson in 1818. Chemically it is fructan made up of fructose units linked by $\beta-2,1$ linkage of which terminal sugar is glucose. In case of inulin, ' $\mathrm{n}$ ' is greater than 2 and less than 60 . Oligofructose, obtained by partial hydrolysis of inulin can be a mixture of molecules. Inulin is a storage polysaccharide that encompasses all linear fructan and is widely distributed in nature. Spectrum of inulin occurrence is reported in more than 36,000 plant species. Some commonly available plants sources like Tubers of Jerusalem artichoke 16-20\%, Leaves of dandelion 12-15, Garlic 9-10\%.

Chicory inulin-type fructans for animal nutrition typically contain $>70 \%$ inulin. Root of the chicory plant (Cichorium intybus L.) normally contains a mixture of short and long chains of fructan with a degree of polymerization (DP) from 11 to 65 . The shorter chain fructan with lower DP is fermented rapidly and significantly promotes Lactobacillus growth, while longer chain fructan with higher DP is fermented more slowly and can reach more distal parts of the GI tract (Macfarlane et al., 2006).

\section{Mechanism of action}

Inulin is neither digested nor absorbed in small intestine but it is selectively and quickly fermented by bacteria in further parts of alimentary tract stimulating proliferation of Lactobacillus and Bifidobacterium. Bifidogenic mechanism of action is based on selective fermentation of fructans by Bifidobacteria through synthesis of betafructosidases enzyme decomposing beta2,1 glycosidic bonds in inulin and oligofructosis as a result of bifidogenic effect change of bacterial microflora in intestine, decrease in number of harmful bacteria is observed. Their proliferation is inhibited by Bifidobacteria that produces short-chain fatty acids (SCFA) and lower $\mathrm{pH}$ of intestinal chyme, with concomitant adverse conditions for pathogens. During bacterial fermentation of fructans SCFA are produced, especially acetic, propionic, lactic and butyric acid. These acids show beneficial effect on metabolism; nourish intestinal cells, lowers $\mathrm{pH}$ of intestinal chyme and increase length of intestinal villus as well as number of epithelial cells in particular villus. These acids reach colon and are highly digestible substrates for bacteria. Ingestion of fructans selectively stimulates the population of bifidobacteria, usually at the expense of clostridia and bacteroides species. Bifidobacterium species are selectively enhanced because of their $\beta$-fructosidase activity, which is selected for the $\beta$ (2-1) glycosidic linkages (de Vries and Stouthamer, 1967). 


\section{Health benefits of prebiotics}

\section{Effect on growth performance}

Grela et al., (2014) observed that feeding a diet with inulin from aqueous-alcoholic extraction and dried Jerusalem artichoke or chicory root showed substantially higher daily body weight gains $(\mathrm{P} \leq 0.05)$ throughout the rearing period until $84 \mathrm{~d}$ of life in piglets. Supplementation of veal calves fed high quality lactose with FOS for short time improved feed conversion ratio and average daily gain (Kaufhold et al., 2000). Quigley et al., (1997) studied effects of spray-dried animal plasma in milk replacer without or with the addition of additives containing fructooligosaccharides and spray-dried serum on health, growth, and intake of Holstein calves.Quigley et al., (1997) reported that average body weight, average body weight gain and feed efficiency was significantly higher $(\mathrm{P}<0.10)$ in calves treated with galactosyl-lactose or antibiotics.

\section{Effect on gut health and feces}

Masanetzet al., (2010) showed the impact of inulin and lactulose supplementation on the intestinal morphology of calves. In jejunum, villus length showed an overall tendency to be decreased in inulin treated animals and to be increased in lactulose treated animals when compared to the control group $(\mathrm{P}<0.05)$. Shorter villi and a decreased proliferation rate may reduce the amount of energy necessary for maintenance of gut architecture thereby providing more energy for growth and fattening. Philippeau et al., (2010) through their in vitro studies of FOS on fermentation pattern and bacterial concentration of ileal contents showed that volatile fatty acid, lactic acid and gas are produced during fermentation of scFOS by microbiota in upper gastrointestinal tract. Their results also showed that number of Bifidobacterium, lactic acid bacteria and Enterococcus decreased with unclear response on Clostridium perfringens count. Chen et al., (2005) studied the effect of oligofructose and inulin. It was observed that reduced the volatile ammonia and fecal $\mathrm{pH}$ in fresh fecal during the first four weeks of production in diet content oligofructose. Little or no effect on volatile ammonia content or fecal $\mathrm{pH}$ were observed for the inulin treatment. No differences $(\mathrm{P}>0.05)$ in moisture contents among the fecal samples were observed throughout the entire experiment. During the 4th week and 5th week, inulin and oligofructose treated broilers had lower fecal moisture contents.

\section{Effect on immune response}

Prebiotics may have direct or indirect effect on some immune mechanism in animals and thus improve animal health and performance. They can directly improve health status through stimulation of the activity of phagocytic cells as well as nonspecific humoral immunity mechanisms. Prebiotic supplementation, including inulin, enhances synthesis and secretory activity of $\operatorname{IgA}$ in the gastrointestinal tract (Girrbach et al., 2005). Schley and Field (2002) showed that the direct contact of lactic acid bacteria or bacterial products with immune cells in the intestine and production of SCFA from fermentation which increase T-cell number in the gastro-intestinal system. The prebiotic also modulate mucin production through increase in the number of goblet cells. Prebiotics can modulate the type and function of cells from Gut Associated Lymphoid Tissue (GALT) especially payer's patches, secondary lymphoid tissues and peripheral circulation (Samal and Behura, 2015). Increase in Bifidobacterium sp. is associated with increased IgA levels in the small intestine. Immune and inflammationmodulating effects of prebiotic substances 
especially for inulin and oligofructose have been reported repeatedly (Hosonoet al., 2003).

Trushina et al., (2005) reported that mice supplemented with 10\% oligofructose or inulin had increased peritoneal macrophage phagocytosis and macrophage superoxide production compared to control mice. They also reported increasing content of interleukin-2 and interleukin-4 in blood in rats fed with inulin and oligofructose. White et al., (2002) reported that level of immunoglobulin increases by supplementation of prebiotics in pigs.

\section{Effect on blood hematology and blood biochemical indices}

Masanetz et al., (2011) reported that lactulose and inulin supplementation in calves resulted in significant decrease in thrombocyte number and lower monocyte proportions. The total leucocytes count was reduced by lactulose and inulin supplementation which resulted in increased hemoglobin and hematocrit concentration. Takagi et al., (2011) reported that there was no significant difference observed in red blood cell and white blood cell counts, hematocrit values, haemoglobin levels and total protein concentrations between the treatment group containing difructose anhydride III (@3g/ administration) and control group. The mean total cholesterol concentration differed significantly $(\mathrm{P}<0.05)$ at Day 14 and the total cholesterol concentration at Day 30 and iron concentration at Day 14 tend to differ between the groups. Also no significant differences were observed in serum BUN, AST, FFA, Ca, Mg, LF, IgA, IgG and IgM levels between the treatment group and control group. Difructose anhydride III treated groups showed significant increase in serum cholesterol level at day 14 and day 30. Ahmdifar et al., (2011) investigated the effects of different dietary prebiotic inulin levels on hematologic and biochemical parameters and some blood serum enzymes in juvenile great sturgeon (Husohuso). The results showed that with the increase in supplementation level of inulin, enzymes and white blood cell count increased significantly.

\section{Effect on antioxidant status}

El-Sayed et al., (2015) studied the effect ofchicory extract to protect against carbon tetrachloride $\left(\mathrm{CCl}_{4}\right)$-induced oxidative stress and hepatotoxicity in male rats. The rats were divided into four groups according to treatment: saline (control); chicory extract $(100 \mathrm{mg} / \mathrm{kg}$ body weight daily, given orally for 2 weeks); CCl4 (1 ml/kg body weight by intraperitoneal injection for 2 consecutive days only); or chicory extract $(100 \mathrm{mg} / \mathrm{kg}$ body weight daily for 2 weeks) $+\mathrm{CCl} 4$ injection on days 16 and 17. The levels of antioxidants, were estimated twenty-four hours after the last CCl4 injection. Pretreatment with chicory extract significantly reduced CCl4-induced elevation and nearly normalized levels of glutathione peroxidase (GPx), catalase (CAT) in the liver. Chicory Compared with untreated controls, rats treated with $\mathrm{CCl} 4$ alone showed significantly $(\mathrm{P}<0.05)$ and decreased activity of the antioxidant enzymes, GPx (65\%),CAT (69\%). In contrast, rats treated with CE alone showed significantly $(\mathrm{P}<0.05)$ increased levels of GPx (107\%) and CAT (104\%).

In conclusion, prebiotic are potential feed additive in case of calf and small animal. The inulinis one of the emerging prebiotic, which is present in several plant like chicory root, Jerusalem artichoke contain $15-16 \%$ of inulin on fresh matter basis. We can use as a source of prebiotic. Inulin will increase growth rate (Body weight, ADG), immunity and antioxidant activity. However, the data on the efficacy of inulin-type fructans are sometimes variable and not yet fully conclusive. 


\section{References}

Abbasi, S. and Farzanmehr, H., 2009. Optimization of extracting conditions of inulin from Iranian artichoke with/without ultrasound using response surface methodology. JWSS., 13: 423-435.

Afzal, S., Afzal, N., Awan, M. R., Khan, T. S., Gilani, A., Khanum, R. and Tariq, S. 2009. Ethno-botanical studies from Northern Pakistan. J. Ayub. Med. Coll. Abbottabad., 21:52-57.

Ahmdifar, E., Akrami, R., Ghelichi, A. and Zarejabad, A. M. 2011. Effects of different dietary prebiotic insulin levels on blood serum enzymes, hematologic, and biochemical parameters of great sturgeon (Husohuso) juveniles. Comp. Clin. Path., 20:447-451.

Atta, N. F., El-Kady, M. F. and Galal, A. 2010. Simultaneous determination of catecholamines, uric acid and ascorbic acid at physiological levels using poly (N-methylpyrrole)/ Pd-nanoclusters sensor. Anal.Biochem., 400: 78-85.

Bais, H. P. and Ravishankar, G. A. 2001. Cichoriumintybus L-cultivation, processing, utility, value addition and biotechnology, with an emphasis on current status and future prospects. J. Food. SciAgri., 81:467-484.

Chen, Y. C., Nakthong, C. and Chen, T. C. 2005.Improvement of laying hen performance by dietary prebiotic chicory oligofructose and inulin.Int.J. Poult. Sci., 4:103-108.

De Vries, W. and Stouthamer, A.H. 1967. Pathway of glucose fermentation in relation to the taxonomy of bifidobacteria. J. Bacteriol., 93: 574576.

El-Sayed, Y. S., Lebda, M. A., Hassinin, M. and Neoman, S. A. 2015. Chicory (Cichorium intybus L.) root extract regulates the oxidative status and antioxidant gene transcripts in CCl4induced hepatotoxicity. Plos One, 10: e0121549.

Girrbach, S., Schröder, B., Breves, G., Rechkemmer, G. and Watzl, B. 2005. Short and long-term supplementation of pre- and probiotics modulate T-cell mediated immunity of the porcine gilt. Faseb. J., 19:444-445.

Grela, E. R., Sobolewska, S., KowalczukVasilev, E. and Krasucki, W. 2014. Effect of dietary inulin source on piglet performance, immunoglobulin concentration, and plasma lipid profile. Bull. Vet. Inst. Pulawy.,58: 453-458.

Heimler, D., Isolani, L., Vignolini, P. and Romani, A. 2009.Polyphenol content and antiradical activity of Cichorium intybus L. from biodynamic and conventional farming. Food chem., 114: 765-770.

Heinrichs, A.J., Jones, C.M. and Heinrichs, B.S.2003. Effects of Mannan oligosaccharide or antibiotics in neonatal diets on health and growth of dairy calves. J. Dairy Sci., 86:40644069.

Hosono, A., Ozawa, A., Kato, R., Ohnishi, Y., Nakanishi, Y., Kimura, T. and Nakamura, R. 2003. Dietary fructooligosaccharides induce immunoregulation of intestinal IgA secretion by murine Peyer's patch cells. Biosci.Biotech.Bioch., 67:758764.

Kaufhold, M., Aninger, H., Berth, M., Speck, J. and Eberhardt, M. 2000. Electrical stress and failure mechanism of the winding insulation in PWM-inverterfed low-voltage induction motors. IEEE, 47:396-402.

Macfarlane, S. M. G. T., Macfarlane, G. T., and Cummings, J. T. 2006. Prebiotics in the gastrointestinal tract. Aliment. 
Pharmacol., 24: 701-714.

Masanetz, S., Preißinger, W., Meyer, H. H. D. and Pfaffl, M. W. 2011. Effects of the prebiotics inulin and lactulose on intestinal immunology and hematology of preruminant calves. Animal, 5: 1099-1106.

Masanetz, S., Wimmer, N., Plitzner, C., Limbeck, E., Preißinger, W. and Pfaffl, M. W. 2010.Effects of insulin and lactulose on the intestinal morphology of calves. Animal, 4:739744.

Milala J., Grezelak, Król B., JuĞkiewicz J. and ZduĚczyk Z. 2009. Composition and properties of chicory extracts rich in fructans and polyphenols. Pol. J. Food Nutr. Sci., 59:35-43

Mulabagal, V., Lang, G. A., DeWitt, D. L., Dalavoy, S. S., and Nair, M. G. 2009.Anthocyanin content, lipid peroxidation and cyclooxygenase enzyme inhibitory activities of sweet and sour cherries. J. Agric. Food Chem., 57:1239-1246.

Muthusamy, V. S., Anand, S., Sangeetha, K. N., Sujatha, S., Arun, B. and Lakshmi, B. S. 2008. Tannins present in Cichorium intybus enhance glucose uptake and inhibit adipogenesis in 3T3-L1 adipocytes through PTP1B inhibition. Chem. Biol. Interact., 174: 69-78.

Ognik, K., and Krauze, M. 2012. Dietary supplementation of mannan oligosaccharides to turkey hens on their growth performance and antioxidant status in the blood. Afr.J.Anim.Sci., 42: 379-388.

Pazola, Z. 1987. The chemistry of cerealbased beverages. Coffee Related Beverages., 5: 59-104.

Philippeau, C., Respondek, F. and Julliand, V. 2010. In vitro effects of fructooligosaccharides on bacterial concentration and fermentation profiles in veal calf ileal contents. Anim. Feed Sci. Technol., 162:83-90.

Saggu, S., Sakeran, M. I., Zidan, N., Tousson, E., Mohan, A. and Rehman, H. 2014. Ameliorating effect of chicory (Chichorium intybus L.) fruit extract against 4-tert-octylphenol induced liver injury and oxidative stress in male rats. Food.Chem.Toxico., 172:138-146.

Samal, L. and Behura, N. C. 2015. Prebiotics: an emerging nutritional approach for improving gut health of livestock and poultry. Asian J. Anim. Vet. Adv.,10: 724-739.

Schley, P. D. and Field, C. J. 2002.The immune-enhancing effects of dietary fibres and prebiotics. Br. J. Nutr., 87: S221-S230.

Trushina, E. N., Mustafina, O. K., Nikitiuk, D. B., Podbel'tsev, D., Mozgovaia, I. N. and Vustina, T. F. 2005.The immune-enhancing effects of oral administration of strains bifidobacteria in experiments. Vopr. Psikhol., 75: 7074.

\section{How to cite this article:}

Anjali Khare, Gaurav Thorat, Veena Mani, Sachin Kumar, Mamata Joysowal, A. Aziz and Supriya Gupta. 2018. Prebiotic Inulin and Fructooligosachride as an Alternative Growth Promoter in Animal. Int.J.Curr.Microbiol.App.Sci. 7(07): 1026-1031. doi: https://doi.org/10.20546/ijcmas.2018.707.124 